\title{
Intravesical administration of pirarubicin against superficial bladder cancer: Relationship between tumor tissue concentration and exposure time in the bladder or therapeutic effect
}

\author{
MAKI ARAKAWA ${ }^{1}$, KOGENTA NAKAMURA $^{2}$, YOSHIAKI YAMADA ${ }^{2}$, KIMIHITO KATO $^{3}$, REMI KATSUDA ${ }^{2}$, \\ MOTOI TOBIUME ${ }^{2}$, KENJI ZENNAMI ${ }^{2}$, MASAYUKI WATANABE ${ }^{2}$, YOSHIHARU KATO ${ }^{2}$, GENYA NISHIKAWA $^{2}$, \\ TAKAHIKO YOSHIZAWA ${ }^{2}$, SHIGEYUKI AOKI ${ }^{2}$, TOMOHIRO TAKI ${ }^{2}$, KENJI MITSUI ${ }^{4}$, \\ NOBUAKI HONDA ${ }^{2}$, HIROKO SAITO ${ }^{1}$ and TAKAAKI HASEGAWA ${ }^{1}$ \\ Departments of ${ }^{1}$ Hospital Pharmacy, and ${ }^{2}$ Urology, Aichi Medical University School of Medicine, Aichi-gun; \\ ${ }^{3}$ Department of Pharmacy, Ichinomiya Municipal Hospital, Ichinomiya; \\ ${ }^{4}$ Department of Urology, Tokoname Municipal Hospital, Tokoname, Aichi, Japan
}

Received May 20, 2011; Accepted June 30, 2011

DOI: $10.3892 / \mathrm{etm} .2011 .315$

\begin{abstract}
The aim of this study was to investigate the relationship between tissue concentrations and exposure times or therapeutic effect of an anthracycline anticancer drug, pirarubicin, in bladder cancer tissue after single intravesical administration against superficial bladder cancer. The concentrations of pirarubicin in tumor tissues and serum were measured at designated collection times after a single intravesical administration of pirarubicin $(30 \mathrm{mg})$ in 22 patients with superficial bladder cancer. A wide range of concentrations of pirarubicin in bladder cancer tissue was observed (2.3-125 $\mu \mathrm{g} / \mathrm{g}$ of tissue), although serum pirarubicin concentrations were not detected in any of the patients. Recurrence of superficial bladder cancer after transurethral resection of the bladder tumor (TUR-BT) was observed in 2 patients (9\%). The concentration of pirarubicin in the tumor tissue tended to be higher as the exposure time increased. There was a weak relationship between the pirarubicin tissue concentration and tumor size. However, no significant relationship between tissue pirarubicin concentrations and the prophylactic effect against intravesical recurrence of bladder cancer after TUR-BT was observed. All patients had no adverse events, such as bladder irritation and local toxicity, caused by the treatment with pirarubicin. These findings suggest that prior to single intravesical administration of pirarubicin to patients with
\end{abstract}

Correspondence to: Dr Maki Arakawa, Department of Hospital Pharmacy, Aichi Medical University School of Medicine, Nagakute-cho, Aichi-gun, Aichi 480-1195, Japan

E-mail: arakawa3@aichi-med-u.ac.jp

Key words: superficial bladder cancer, intravesical chemotherapy, pirarubicin, tumor tissue concentration, exposure time, prophylactic effect against recurrence superficial bladder cancer the exposure time and tumor size should be considered.

\section{Introduction}

Superficial bladder cancer is mainly treated by transurethral resection of the bladder tumor (TUR-BT). Yet, the intravesical recurrence rate of bladder cancer after TUR-BT is reported to be $50-70 \%$ (1-3). Therefore, prophylaxis of the high frequency of recurrence after TUR-BT is important. Bacillus CalmetteGuérin (BCG), doxorubicin, mitomycin, epirubicin, thiotepa and pirarubicin are currently used as intravesical instillation chemotherapy agents to reduce the recurrence rate of bladder cancer (4-13).

Pirarubicin (Fig. 1), an anthracycline drug which has been shown to have a high affinity to bladder tumor cells or tissues (14-16), is a drug used widely for intravesical instillation chemotherapy. The concentration of pirarubicin in the tumor tissue becomes markedly high in a relatively short time after administration into the bladder (15). It is reported that the intravesical instillation with pirarubicin produces an antitumor effect against bladder cancer, and that the prophylactic effect of recurrence in the bladder after intravesical instillation chemotherapy with pirarubicin is higher than that after TUR-BT only (17). Moreover, short-time intravesical instillation chemotherapy is performed to obtain a greater antitumor effect and to prevent an increase in side effects, as this method has the advantage of a higher penetration of pirarubicin into bladder tumor tissues (18).

Conditions for optimal injection of pirarubicin, a concentration-dependent anticancer drug, has yet to be established. The role involving the exposure time of the bladder to pirarubicin in the prophylactic effect against recurrence of bladder cancer has been extensively studied (17-19), whereas the contribution of the concentration of pirarubicin in bladder tumor tissue to the prophylactic effect against recurrence of bladder cancer remains unclear. 
As part of a program for the development of guidelines for the safe use of pirarubicin and effective intravesical chemotherapy with pirarubicin for the prevention of recurrence of bladder cancer, the present study investigated the relationship between the concentration of pirarubicin in bladder tumor tissues and its exposure time in the bladder or therapeutic effect after intravesical instillation chemotherapy with pirarubicin.

\section{Materials and methods}

Patients. Characteristics of the patients enrolled in this study are summarized in Table I. Twenty-two patients with superficial bladder cancer, who were hospitalized in the Department of Urology of Aichi Medical University Hospital, Tokoname Municipal Hospital and Sakashita Hospital, between August 2008 and March 2010, participated in this study. The patients included 21 males and 1 female, aged 51-92 years (mean 70). All patients were diagnosed with transitional cell carcinoma with papillary and initial and primary tumors with superficial $(\mathrm{Ta}, \mathrm{T1})$ tumors and a non-invasive tumor. From histopathological findings, the tumor grade was found to be G1 in 5 patients and G2 in 17 patients. The tumor stage was shown to be pT1 in 2 patients and pTa in 20 patients. Solitary and multiple tumors were found in 17 and 5 patients, respectively. The study was approved by the Institutional Review Board of Aichi Medical University School of Medicine, and written informed consent was obtained for all participants prior to enrollment in the study.

Drugs. Pirarubicin injection (therarubicin, $10 \mathrm{mg} / 20 \mathrm{mg}$ of pirarubicin per injection; Meiji Seika, Tokyo, Japan) and pirarubicin hydrochloride (Wako Chemicals, Tokyo, Japan) were used in this study. Pirarubicin $(30 \mathrm{mg}$ ) was dissolved in $30 \mathrm{ml}$ of distilled water for the injection $(1 \mathrm{mg} / \mathrm{ml})$. All other reagents were commercially available, of analytical grade, and were used without further purification.

Drug administration. Pirarubicin (30 mg) was administered transurethrally for $8 \mathrm{~min}$ in 1 patient, $9 \mathrm{~min}$ in 1 patient, $10 \mathrm{~min}$ in 1 patient, $15 \mathrm{~min}$ in 3 patients, $20 \mathrm{~min}$ in 2 patients, $25 \mathrm{~min}$ in 1 patient, $30 \mathrm{~min}$ in 10 patients and $35 \mathrm{~min}$ in 1 patient (Table II). Bladder cancer tissue and blood samples were collected at the designated intervals described above. The removed bladder cancer tissues were washed immediately with ice-cold saline five times. The washed tissue and serum samples obtained from the patients were stored at $-80^{\circ} \mathrm{C}$ until analysis.

Drug analysis. The pirarubicin concentrations in the plasma and tissue were determined by high-performance liquid chromatography (HPLC). The apparatus used for HPLC was a Shimadzu LC-10A system (Kyoto, Japan) equipped with a fluorescence detector (RF-10AXL; Shimadzu) (excitation, $273 \mathrm{~nm}$; emission, $464 \mathrm{~nm}$ ) consisting of an LC-10A liquid pump and an SIL-10A autoinjector. The conditions were as follows: column, a Cosmocil 5C18 column ( 4.6 by $150 \mathrm{~mm}$; Nacalai Tesque, Kyoto, Japan); mobile phase, $20 \mathrm{mM}$ potassium dihydrogen phosphate-acetonitrile [1:1 ( $\mathrm{vol} / \mathrm{vol})]$ solution; column temperature (CTO-10AC; Shimadzu), $50^{\circ} \mathrm{C}$; flow rate, $1.0 \mathrm{ml} / \mathrm{min}$.

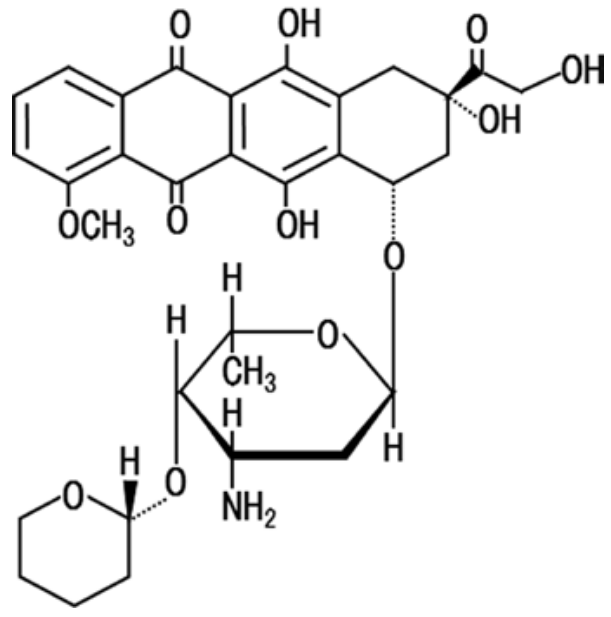

Figure 1. Structure of pirarubicin.

Table I. Characteristics of the patients enrolled in this study.

\begin{tabular}{lc}
\hline Patients & \\
Males & 21 \\
Females & 1 \\
Age, in years & \\
Range & $51-92$ \\
Mean & 70.0 \\
Tumors & \\
Solitary & 17 \\
Multiple (2) & 5 \\
Grade & \\
G1 & 5 \\
G2 & 17 \\
Stage & \\
pTa & 20 \\
pT1 & 2 \\
\hline
\end{tabular}

Each bladder tissue sample (0.002-0.215 g) was weighed and homogenized with ice-cold saline using a tight homogenizer (20 strokes up and down) and adjusted to $0.5,1$ or $2 \mathrm{ml}$ by saline according to each tumor weight. Each sample (100 $\mu \mathrm{l}$ ) of serum and diluted tissue homogenates, $50 \mu \mathrm{l}$ of $0.1 \mathrm{M} \mathrm{NaHCO}_{3}$-saturated $\mathrm{NaCl}$ solution and $150 \mu \mathrm{l}$ of acetonitrile were mixed vigorously and centrifuged at $21.880 \mathrm{x} \mathrm{g}$ for $10 \mathrm{~min}$ at $4^{\circ} \mathrm{C}$. After centrifugation, the supernatant $(50 \mu \mathrm{l})$ was injected into the column.

The standard curves for this assay were shown to be linear for the concentrations measured $(500,1,000,2,000$ and $4,000 \mathrm{ng} / \mathrm{ml}$ ) with a correlation coefficient of 0.999 . The within-day and between-day coefficients of variation $(\mathrm{CV})$ for this assay were $<8 \%$. No interference with the peak of pirarubicin was observed in any samples. The quantitative limit of this assay was $500 \mathrm{ng} / \mathrm{ml}$.

Clinical evaluation. Adverse events, such as frequent urination, pain on urination, hematuria and a feeling of residual urine were observed. The frequency and severity of these 
Table II. Characteristics of the patients that received single intravesical therapy with pirarubicin.

\begin{tabular}{|c|c|c|c|c|c|c|c|c|c|c|}
\hline Patient & Gender & $\begin{array}{c}\text { Age } \\
\text { (years) }\end{array}$ & Grade & Stage & $\begin{array}{l}\text { No. of } \\
\text { tumors }\end{array}$ & $\begin{array}{l}\text { Size } \\
(\mathrm{mm})\end{array}$ & $\begin{array}{l}\text { Retention } \\
\text { time (min) }\end{array}$ & $\begin{array}{c}\text { Concentration } \\
(\mu \mathrm{g} / \mathrm{g} \text { tissue })\end{array}$ & Recurrence & $\begin{array}{c}\text { Follow-up } \\
\text { (months) }\end{array}$ \\
\hline 1 & M & 66 & $\mathrm{G} 2$ & $\mathrm{pTa}$ & 1 & 50 & 8 & 10.6 & + & 3 \\
\hline 2 & M & 85 & $\mathrm{G} 2$ & pT1 & 1 & 24 & 9 & 44.4 & - & 16 \\
\hline 3 & M & 67 & G1 & $\mathrm{pTa}$ & 2 & 20 & 9 & 5.6 & - & 17 \\
\hline 4 & M & 75 & $\mathrm{G} 2$ & $\mathrm{pTa}$ & 1 & 39 & 10 & 7.7 & $\mathrm{x}$ & $\mathrm{x}$ \\
\hline 5 & M & 74 & G1 & $\mathrm{pTa}$ & 1 & 15 & 12 & 16.9 & - & 13 \\
\hline 6 & M & 70 & G2 & $\mathrm{pTa}$ & 2 & 19 & 15 & 65.6 & $\mathrm{x}$ & $\mathrm{x}$ \\
\hline 7 & M & 72 & $\mathrm{G} 2$ & $\mathrm{pTa}$ & 1 & 15 & 15 & 20.4 & - & 14 \\
\hline 8 & M & 54 & G2 & $\mathrm{pTa}$ & 1 & 5 & 15 & 13.9 & - & 20 \\
\hline 9 & M & 53 & G2 & $\mathrm{pTa}$ & 2 & 24 & 20 & 4.9 & - & 14 \\
\hline 10 & $\mathrm{~F}$ & 58 & G2 & $\mathrm{pTa}$ & 1 & 20 & 20 & 17.9 & $\mathrm{x}$ & $\mathrm{x}$ \\
\hline 11 & M & 67 & G2 & $\mathrm{pTa}$ & 1 & 17 & 25 & 23.0 & - & 13 \\
\hline 12 & M & 92 & G2 & $\mathrm{pTa}$ & 1 & 15 & 30 & 13.8 & - & 29 \\
\hline 13 & M & 51 & G2 & $\mathrm{pTa}$ & 1 & 30 & 30 & 2.3 & - & 29 \\
\hline 14 & M & 71 & G2 & pT1 & 2 & 34 & 30 & 47.7 & + & 5 \\
\hline 15 & M & 80 & G2 & $\mathrm{pTa}$ & 1 & 15 & 30 & 4.7 & - & 29 \\
\hline 16 & M & 87 & G2 & $\mathrm{pTa}$ & 1 & 23 & 30 & 125.0 & $\mathrm{x}$ & $\mathrm{x}$ \\
\hline 17 & M & 73 & G1 & $\mathrm{pTa}$ & 1 & 10 & 30 & 79.6 & - & 26 \\
\hline 18 & M & 61 & G1 & $\mathrm{pTa}$ & 1 & 15 & 30 & 11.9 & - & 14 \\
\hline 19 & M & 65 & G2 & $\mathrm{pTa}$ & 1 & 13 & 30 & 26.7 & - & 26 \\
\hline 20 & M & 81 & G2 & pTa & 2 & 8 & 30 & 16.3 & $\mathrm{x}$ & $\mathrm{x}$ \\
\hline 21 & M & 71 & G1 & $\mathrm{pTa}$ & 1 & 5 & 30 & 125.0 & - & 20 \\
\hline 22 & M & 67 & $\mathrm{G} 2$ & $\mathrm{pTa}$ & 1 & 6 & 35 & 45.9 & - & 10 \\
\hline
\end{tabular}

Recurrence was observed for 1 year after TUR-BT. x, not followed up.

events were also investigated. The therapeutic effect was evaluated between the date of surgery and January 2011 for the non-recurrence period. Cystoscopy and urinary cytology in all patients were performed at 3-month intervals during the first year.

Statistical analysis. Data are represented as observed values. Statistical analysis was performed using Stat View (Abacus Concept, Barkeley, CA, USA).

\section{Results}

Various clinical data for each patient receiving a single intravesical therapy with pirarubicin are summarized in Table II. Concentrations of pirarubicin in bladder cancer tissues showed a wide range from 2.3 to $125 \mu \mathrm{g} / \mathrm{g}$ tissue, whereas no serum concentrations of pirarubicin were observed in any of the patients.

Weak relationships, not statistically significant, were observed between pirarubicin tissue concentrations and exposure time of pirarubicin in the bladder or tumor size. As shown in Fig. 2A, the concentration of pirarubicin in tumor tissues tended to be higher as the exposure time was prolonged, whereas the concentration tended to be lower as the tumor size increased (Fig. 2B). However, there was no relationship between pirarubicin tissue concentrations and prophylactic effect against recurrence of bladder cancer after TUR-BT.
No severe adverse events caused by treatment with pirarubicin were noted in all patients.

\section{Discussion}

There is no detailed information regarding the effect of the exposure time of pirarubicin in the bladder on tissue concentrations in patients with superficial bladder cancer. In the present study, to evaluate this issue, the concentrations of pirarubicin were measured in the tumor tissues and serum at different collection times after a single intravesical administration of pirarubicin in 22 patients with superficial bladder cancer.

In the present study, a weak relationship between pirarubicin tissue concentrations and exposure time of pirarubicin in the bladder or tumor size was observed. Unexpectedly, the concentrations of pirarubicin in the tumor tissues had a tendency to be lower as the tumor size increased, indicating that the uptake of pirarubicin into tumor tissue decreases as the tumor size increases. We postulated the possibility that concentrations of pirarubicin in the bladder did not reach a steady state. The present study found that in the 2 patients who presented with a recurrence of bladder cancer the tumor size was larger than $30 \mathrm{~mm}$. These results corroborate those of Kanayama et al (20), who reported that a higher incidence of the recurrence of bladder cancer was observed in patients having 5 or more tumors, or in patients with a tumor size larger than $30 \mathrm{~mm}$. Therefore, tumor size should be considered when 

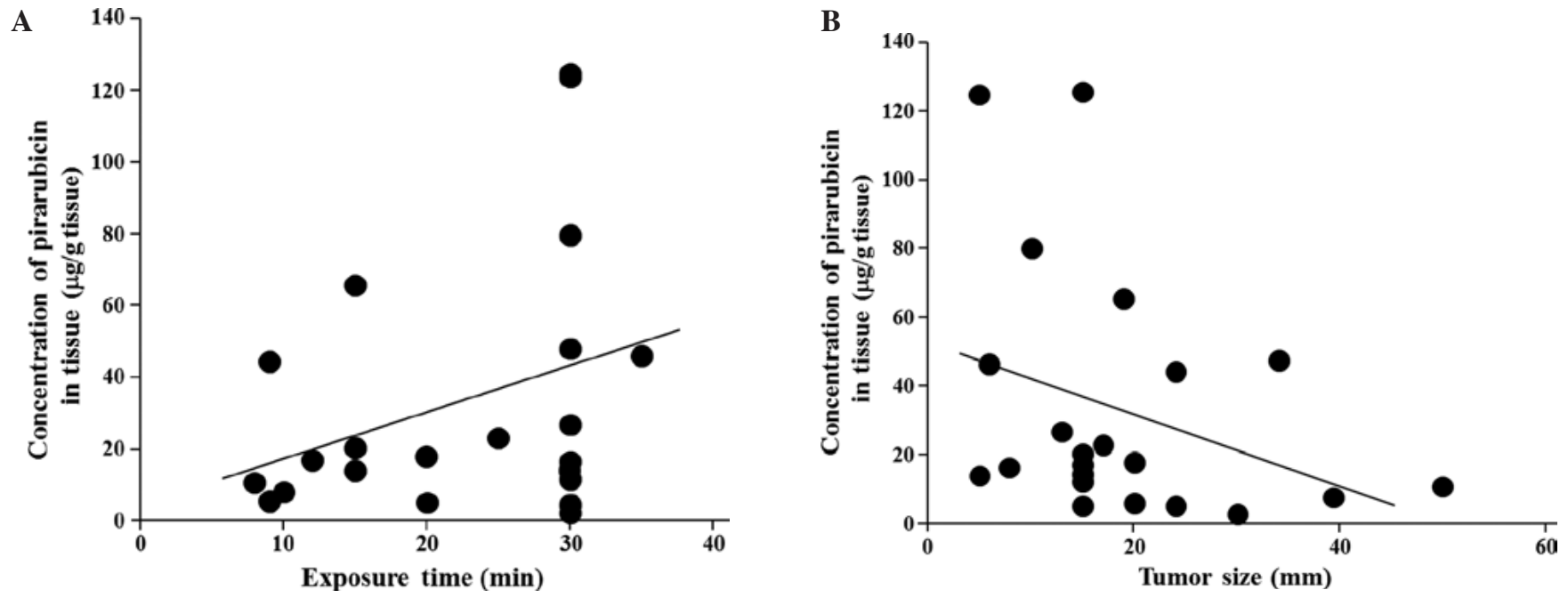

Figure 2. (A) Relationship between tissue concentrations of pirarubicin and exposure time in the bladder. The regression line was calculated as $y=1.25 \mathrm{x}+5.15$. The correlation coefficient (r) was 0.316. (B). Relationship between tissue concentrations of pirarubicin and tumor size. The regression line was calculated as $y=-1.05 x+52.9$. The correlation coefficient $(r)$ was 0.327 .

intravesical chemotherapy with pirarubicin against superficial bladder cancer is conducted. Assuming that pirarubicin is distributed into tumor tissues by a passive diffusion system, we should consider the presence of an efflux pump in cases of tissues of small tumors exhibiting lower concentrations of pirarubicin. The susceptibility of pirarubicin to tumor tissues of each patient should also be considered.

There are several reports regarding the involvement of certain efflux drug transporters in bladder cancer (21-25). It is well known that one of the drug transporters, ABCB1/ P-glycoprotein, an ATP-binding cassette transporter protein, acts as an efflux pump for various drugs, such as Vinca alkaloid and anthracycline anticancer drugs. This transporter is expressed in anticancer drug-resistant tumor cells. In the present study, relatively low concentrations of pirarubicin in bladder tumor tissues were observed in several patients who were administered well-known P-glycoprotein substrates, such as atorvastatin, fexofenadine, diltiazem and itraconazole. Considering that pirarubicin is a typical P-glycoprotein substrate, the observed low concentrations of pirarubicin in bladder tissues may be explained by efflux of pirarubicin from tumor tissues overexpressing P-glycoprotein or by efflux of pirarubicin by competitive inhibition of P-glycoprotein substrates. These observations suggest the need to measure the expression levels of P-glycoprotein in the tumor tissues of each patient before initiating intravesical chemotherapy with pirarubicin.

The present findings are, at least in part, supported by the results of Maruyama et al (26), who reported that the growth of T-24 cells in vitro was inhibited by the presence of pirarubicin in a dose- and time-dependent manner. The present results corroborate those of Yamamoto et al (27), who reported that pirarubicin was not detected in the plasma after single intravesical administration of pirarubicin, and by a report by Okamura et al (17), who reported that there were no severe local toxicities after a single dose of pirarubicin for $60 \mathrm{~min}$.

In conclusion, the results obtained from the present study suggest that the concentration of pirarubicin in bladder cancer tissue appears to be dependent on the exposure time of pira- rubicin in the bladder after single intravesical administration. Considering that intravesical administration of anticancer drugs is useful for the therapy of superficial bladder cancer with considerably high recurrence, further studies are required to investigate the optimal dosage regimen for intravesical administration of pirarubicin using a large number of patients with superficial bladder cancer.

\section{References}

1. Lutzeyer W, Rubben H and Dahm H: Prognostic parameters in superficial bladder cancer: an analysis of 315 cases. J Urol 127: 250-252, 1982.

2. Herr HW, Laudone VP and Whitmore WF: An overview of intravesical therapy for superficial bladder tumors. J Urol 138: 1363-1368, 1987.

3. Miki T, Nonomura N, Kojima Y, et al: A randomized study on intravesical pirarubicin (THP) chemoprophylaxis of recurrence after transurethral resection of superficial bladder cancer. Hinyokika Kiyo 43: 907-912, 1997 (In Japanese).

4. Sylvester RJ, van der MA and Lamm DL: Intravesical bacillus Calmette-Guerin reduces the risk of progression in patients with superficial bladder cancer: a meta-analysis of the published results of randomized clinical trials. J Urol 168: 1964-1970, 2002.

5. Lamm DL, Blumenstein BA, Crawford ED, et al: A randomized trial of intravesical doxorubicin and immunotherapy with bacille Calmette-Guérin for transitional-cell carcinoma of the bladder. N Engl J Med 325: 1205-1209, 1991.

6. Witjes JA, Meijden AP, Sylvester LC, Debruyne FM, van Aubel A and Withes WP: Long-term follow-up of an EORTC randomized prospective trial comparing intravesical bacilli CalmetteGuerin-RIVM and mitomycin $\mathrm{C}$ in superficial bladder cancer. EORTC GU Group and the Dutch South East Cooperative Urological Group. European Organisation for Research and Treatment of Cancer Genito-Urinary Tract Cancer Collaborative Group. Urology 52: 403-410, 1998.

7. Soloway MS, Sofer M and Vaidya A: Contemporary management of stage T1 transitional cell carcinoma of the bladder. J Urol 167: 1573-1583, 2002.

8. Oosterlinck W, Kurth KH, Schröder F, Bultinck J, Hammond B and Sylvester R, Members of the European Organization for Research and Treatment of Cancer Genitourinary Group: A prospective European organization for research and treatment of cancer genitourinary group randomized trial comparing transurethral resection followed by a single intravesical instillation of epirubicin or water in single stage Ta, $\mathrm{T} 1$ papillary carcinoma of the bladder. J Urol 149: 749-752, 1993. 
9. Tolley DA, Parmar MK, Grigor KM, et al: The effect of intravesical mitomycin $C$ on recurrence of newly diagnosed superficial bladder cancer: a further report with 7 years of follow-up. J Urol 155: 1233-1238, 1996.

10. Rajala P, Liukkonen T, Raitanen M, Rintala E, Kaasinen E, Helle $\mathrm{M}$ and Lukkarinen $\mathrm{O}$ : Transurethral resection with perioperative instillation of interferon- $\alpha$ or epirubicin for the prophylaxis of recurrent primary superficial bladder cancer: a prospective randomized multicenter study-Finnbladder III J Urol 161: 1133-1136, 1999.

11. Solsona E, Iborra I, Ricós JV, Monrós L, Casanova J and Dumont R: Effectiveness of a single immediate mitomycin C instillation in patients with low risk superficial bladder cancer: short and long-term followup. J Urol 161: 1120-1123, 1999.

12. Zincke H, Utz DC, Taylor WF, Myers RP and Leary FJ: Influence of thiotepa and doxorubicin instillation at time of transurethral surgical treatment of bladder cancer on tumor recurrence: a prospective, randomized double-blind, controlled trial. J Urol 129: 505-509, 1983.

13. Prout GR, Koontz WW, Coomms LJ, Hawkins IR and Friedell GH: Long-term fate of 90 patients with superficial bladder cancer randomly assigned to receive or not to receive thiotepa. J Urol 130: 677-680, 1983.

14. Fukushima T, Ueda T and Nakamura T: Pharmacokinetics and action mechanism of anthracyclines. Gan To Kagaku Ryoho 19: 445-450, 1992 (In Japanese).

15. Akaza H, Niijima T, Hisamatsu T and Fujigaki M: Comparative investigation on use of (2"R)-4'-O-tetrahydropyranyl-adriamycin and adriamycin as intravesical chemotherapy for superficial bladder tumors. Urology 32: 141-145, 1988.

16. Kunimoto S, Miura K, Takahashi Y, Takeuchi T and Umezawa $\mathrm{H}$ Rapid uptake by cultured tumor cells and intracellular behavior of 4-O-tetrahydropyranyladriamycin. J Antibiot 36: 3123-3117, 1983 (In Japanese).

17. Okamura K, Ono Y, Kinukawa T, et al: Nagoya University Urological Oncology Group. Randomized study of single early instillation of (2"R)-4-O-tetrahydropyranyl-doxorubicin for a single superficial bladder carcinoma. Cancer 94: 2363-2368, 2002.

18. Nakagawa S, Kojima M, Takeda H, Sugimoto K, Mikami K and Watanabe H: Short-duration bladder instillation therapy with pirarubicin for superficial bladder tumor based on pharmacodynamic study. Gan To Kagaku Ryoho 19: 1837-1877, 1992 (In Japanese).
19. Sugano O, Hatakeyama $\mathrm{T}$ and Kato $\mathrm{H}$ : Investigation of retention time of intravesical instillation therapy with pirarubicin (THP). Gan To Kagaku Ryoho 23: 1169-1174, 1996 (In Japanese).

20. Kanayama H, Yokota K, Kurokawa Y, et al: Postoperative prophylactic intravesical instillation of tetrahydropyranyl-adriamycin (THP) for superficial bladder cancer. Gan To Kagaku Ryoho 26: 651-655, 1999 (In Japanese).

21. Kuwano M, Toh S, Uchiumi T, Takano H, Kohno K and Wada M: Multidrug resistance-associated protein subfamily transporters and drug resistance. Anticancer Drug Des 14: 123-131, 1999.

22. Hasegawa $\mathrm{S}$, Abe T, Naito $\mathrm{S}$, et al: Expression of multidrug resistance-associated protein (MRP), MDR1 and DNA topoisomerase II in human multidrug-resistant bladder cancer cell lines. Br J Cancer 71: 907-913, 1995.

23. Kimiya K, Naito S, Soejima T, Sakamoto N, Kotoh S, Kumazawa $\mathrm{J}$ and Tsuruo T: Establishment and characterization of doxorubicin-resistant human bladder cancer cell line, KK47/ ADM. J Urol 148: 441-445, 1992.

24. Naito S, Kotoh S, Omoto T, et al: The Kyushu University Urological Oncology Group: Prophylactic intravesical instillation chemotherapy against recurrence after a transurethral resection of superficial bladder cancer: a randomized controlled trial of doxorubicin plus verapamil versus doxorubicin alone. Cancer Chemother Pharmacol 42: 367-372, 1998.

25. Tada Y, Wada M, Migita T, et al: Inceased expression of multidrug resistance-associated proteins in bladder cancer drug clinical course and drug resistance to doxorubicin. Int J Cancer 98: 630-635, 2002

26. Maruyama T, Higuchi Y, Suzuki T, Qiu J, Yamamoto S and Shima H: Double short-time exposure to pirarubicin produces higher cytotoxicity against T24 bladder cancer cells. J Infect Chemother 17: 11-16, 2010.

27. Yamamoto Y, Nasu Y, Saika T, Aaeda T, Tsushima T and Kumon $\mathrm{H}$ : The absorption of pirarubicin instilled intravesicaly immediately after transurethral resection of superficial bladder cancer. BJU Int 86: 802-804, 2000. 